\title{
“A sweet smile": The modulatory role of emotion in how extrinsic factors influence taste evaluation
}

Qian (Janice) Wang \& Charles Spence

Crossmodal Research Laboratory, Department of Experimental Psychology,

University of Oxford, Oxford, United Kingdom

CORRESPONDENCE TO: Qian (Janice) Wang, Crossmodal Research Laboratory, Department of Experimental Psychology, University of Oxford, New Radcliffe House, Oxford, OX2 6BW, U.K. TEL: +44-1865-271307 FAX: +44-1865-310447; EMAIL: qian.wang@psy.ox.ac.uk 


\section{"A sweet smile": The modulatory role of emotion in how extrinsic factors influence taste evaluation}

It has recently been demonstrated that the reported tastes/flavours of food/beverages can be modulated by means of external visual and auditory stimuli such as typeface, shapes, and music. The present study was designed to assess the role of the emotional valence of the product-extrinsic stimuli in such crossmodal modulations of taste. Participants evaluated samples of mixed fruit juice whilst simultaneously being presented with auditory or visual stimuli having either positive or negative valence. The soundtracks had either been harmonised with consonant (positive valence) or dissonant (negative valence) musical intervals. The visual stimuli consisted of images of emotional faces from the International Affective Picture System (IAPS) with valence ratings matched to the soundtracks. Each juice sample was rated on two computerbased scales: One anchored with the words sour and sweet, while the other scale required hedonic ratings. Those participants who tasted the juice sample while presented with the positively-valenced stimuli rated the juice as tasting sweeter compared to negatively-valenced stimuli, regardless of whether the stimuli were visual or auditory. These results suggest that the emotional valence of foodextrinsic stimuli can play a role in shaping food flavour evaluation and liking.

Keywords: crossmodal correspondences; facial emotions; harmony; taste; sensation transfer; hedonic correspondences. 


\section{Introduction}

Recently, various studies have started to demonstrate robust associations between taste/flavour attributes and external visual (see Velasco, Salgado-Montejo, Marmolejo-Ramos, \& Spence, 2014, for a review) as well as auditory stimuli (see Knöferle \& Spence, 2012, for a review). For instance, sweetness and sweet-tasting foods tend to be associated with rounded typeface and packaging shapes, softer speech sounds, and harmonically consonant music; whereas sourness is associated with angular typeface and packaging shapes, sharper speech sounds, and harmonically dissonant music (Knoeferle, Woods, Käppler, \& Spence, 2015; Mesz, Trevisan, \& Sigman, 2011; Ngo et al., 2013; Salgado-Montejo et al., 2015a; Velasco et al., 2014; Velasco, Woods, Hyndman, \& Spence, 2015). Beyond mere associations, looking at curved shapes has been demonstrated to enhance sweet sensitivity compared to angular shapes (Liang, Roy, Chen, \& Zhang, 2013; Liang et al., 2016). Similarly, listening to soundtracks with auditory attributes that correspond to sweetness (Wang, Woods, \& Spence, 2015) can alter the reported level of sweetness in the food itself (e.g., Crisinel \& Spence, 2012; Reinoso Carvalho, Wang, Van Ee, \& Spence, 2016; Reinoso Carvalho, Wang, Van Ee, Persoone, \& Spence, 2017; Spence, Velasco, \& Knoeferle, 2014; Wang, Keller, \& Spence, 2017).

While the mechanism(s) underlying this taste modulation effect is(are) as yet unknown, one possibility is that the visual and auditory cues are somehow priming (or triggering) certain emotions in the mind of the participant. Consequently, the participants might then transfer these emotions to the food/drink that they happen to the tasting. For instance, we recently demonstrated that harmonic consonance was associated with sweetness whereas harmonic dissonance was associated with sourness instead (Wang \& Spence, 2016). Furthermore, participants in their study rated the 
same juice mixture as sweeter or more sour (and also more or less liked) depending on whether the melody was harmonized with consonant or dissonant intervals. Neurologically, consonant and dissonant musical intervals are deeply ingrained in low-level sensory processing; various degrees of consonance and dissonance have enhanced activity in the paralimbic and neocortical regions responsible for processing pleasant/unpleasant emotional states (Blood, Zatorre, Bermudez, \& Evans, 1999). According to the sensation transfer theory (Cheskin, 1957; Spence \& PiquerasFiszman, 2014), it is plausible that any positive feelings induced by consonant music (and equally, any negative emotions induced by the dissonant music) may simply have been transferred to the juice-rating task, thus resulting in higher reported pleasantness (and sweetness) ratings for the juice.

As further justification for the sensation transfer theory, it is well-known that people's emotional perception of stimuli in one sensory modality can be altered by the emotional information presented in another; for instance, vocally expressed affective information has been shown to bias the interpretation of facial emotions (de Gelder \& Vroomen, 2000; Ethofer et al., 2006; Massaro \& Egan, 1996), postures (Van den Stock, Righart, \& de Gelder, 2007), and body movements (Van den Stock, Grèzes, \& de Gelder, 2008). In terms of musical stimuli, music-elicited emotion has been shown to influence people’s processing of facial expressions (Logeswaran \& Bhattacharya, 2009).

In order to test the theory that taste/flavour evaluation can be modulated by the emotion content of external stimuli, we decided to extend our previous work by running a version of Wang and Spence's (2016) study while at the same time introducing emotional visual stimuli - specifically, images of faces expressing either positive or negative emotion. Human faces offer one of the clearest ways of 
demonstrating emotion and have been used in studies across multiple disciplines (e.g., Becerril \& Barch, 2011; Carminati \& Knoeferle, 2013; Derntl et al., 2009; Palmer, Schloss, Xu, \& Prado-León, 2013). With regards to food/drink, smile-like concave lines enhance product preference as compared to frown-like convex lines (SalgadoMontejo, Leon, Elliot, Salgado, \& Spence, 2015b). Behaviourally, even happy faces that have only been presented subliminally can cause participants to consume more beverages and increase their willingness to pay, compared to angry faces (Winkielman, Berridge, \& Wilbarger, 2005).

If images of emotional faces - with similar valence ratings as the consonant/dissonant soundtracks - were to induce a similar taste modulation effect as the soundtracks, this would provide evidence to support the suggestion that the mechanism behind the results reported in our previous study (Wang \& Spence, 2016) involved some kind of sensation transfer. The visual images in the present study were chosen from the International Affective Picture System (IAPS) to have similar valence ratings as the consonant/dissonant soundtracks in our previous study. IAPS is an on-going effort at the NIHM Center for the Study of Emotion and Attention to create and distribute stimuli with standardised emotion ratings (valence, arousal, and dominance) for use in studies of emotion and attention (Lang, Bradley, \& Cuthbert, 2008).

In the present study, the experimental hypothesis was that if participants are influenced by the emotional content of what they see or hear, then a fruit beverage tasted while exposed to positive external stimuli - regardless of their modality should be liked more and rated as sweeter. Likewise, it is expected that exposure to the negative stimuli should induce a sourer taste rating and diminished liking of the beverage. 


\section{Methods and materials}

\section{Participants}

A total of $49^{1}$ participants (36 women, 13 men) aged $18-60$ years $(M=30.86$, $S D=10.98$ ) took part in the study. The participants were recruited at the Food Matters Live conference at the London ExCeL Centre, November 22, 2016. All of the participants gave their informed consent to take part in the study. None of the participants reported a cold, or any other known impairment of their sense of smell, taste, or hearing at the time of the study. The study was approved by the Central University Research Ethics Committee of Oxford University (MSD-IDREC-C1-2014205).

\section{Auditory stimuli}

Consonant and dissonant versions of a short melody were created. The consonant version was harmonised with major and minor thirds (three and four half-steps, respectively), while the dissonant version was harmonised with minor second intervals (one half-step). The music scores were created using the MuseScore software and exported to MIDI format, and instrumented using GarageBand's Steinway Grand Piano plugin. The same soundtracks were also used by Wang and Spence (2016) and are associated with different tastes (on a 10 point sour-sweet scale, $M_{\text {consonant }}=6.78, M_{\text {dissonant }}=3.27$ ) and different pleasantness ratings (on a 10 point unpleasant-pleasant scale, $M_{\text {consonant }}=5.23, \quad M_{\text {dissonant }}=2.51$ ). The sounds can be downloaded from https://soundcloud.com/janicewang09/sets/harmony.

\section{Visual stimuli}

\footnotetext{
${ }^{1}$ A sample size calculation (using 0.05 for alpha level and 0.80 for Power) was performed, based on data from Wang and Spence (2016) for mean $\left(\mathrm{M}_{\text {consonant }}=4.09\right.$, $\left.\mathrm{M}_{\text {dissonant }}=4.87\right)$ and standard deviation $\left(\mathrm{SD}_{\text {consonant }}=1.63, \mathrm{SD}_{\text {dissonant }}=1.96\right)$ values of sweet-sour ratings under consonant versus dissonant music. The correlation between the means was 0.33 , yielding a sample size of 47 .
} 
Two images, showing the face of a crying and laughing child, respectively, were chosen from the International Affective Picture System (IAPS) (Lang et al., 2008), slide numbers 2900.1 and 2900.2. The two images were chosen because they were identical except for the facial expressions of the child, and because they had very different valence ratings (on a scale of $1-9, \quad M_{\text {valence_2900.1 }}(S D)=2.56(1.41)$,

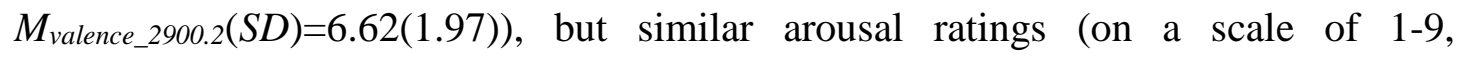
$\left.M_{\text {arousal_2900.1 }}(S D)=4.61(2.07), M_{\text {arousal_2900.2(SD) }}=4.52(1.92)\right)$.

\section{Taste stimuli}

A juice mixture was prepared with a blend of 2:2:1 ratio Tropicana white grapefruit juice, Sainsbury's ${ }^{2}$ smooth orange juice, and Sainsbury's apple juice. This was the same ratio of juices as used in Wang and Spence (2016, Experiment 1). A juice mixture was used instead of a single juice in order to minimize the possibility that the participants would guess the nature of the juice sample and hence perhaps feel overconfident in giving their responses, especially given the within-participants nature of the experimental design. Each sample consisted of $15 \mathrm{~mL}$ of juice and was served in a transparent plastic shot glass. Each participant received four samples, served on a white Styrofoam plate with 3-digit labels.

\section{Procedure}

The study was designed with valence (pleasant or unpleasant sound or visual image) and modality (sound or image) as the within-participants factors. Each participant completed four trials and experienced all four of the stimuli.

Each participant was seated in front of a computer screen with headphones, a plate with four juice samples (labelled with 3-digit identifiers 719, 420, 536, and 148), and

\footnotetext{
${ }^{2}$ Sainsbury's is a UK-wide supermarket chain.
} 
a cup of water to cleanse their palates. The experiment was programmed on the Qualtrics online survey platform and the participants responded by using the mouse to click or drag the indicator on the continuous rating scales. Participants were randomly assigned to experience either the two visual stimuli first or the two auditory stimuli first. For the visual stimuli, the participants had to taste the juice sample while looking at the image. For the auditory stimuli, the participants were asked to play the sound clip and taste the juice sample once they could hear the music. For each trial, the participants were instructed to keep the entire juice sample in their mouths for the 15-second duration of the tasting period. They were instructed to swish the sample around in their mouths and swallow at the end of the tasting period. Next, the participants navigated to a new page and evaluated the juice sample on an 11-point sour-sweet balance scale $(0=$ much more sour than sweet, $5=$ =balanced, $10=$ much more sweet than sour) and an 11-point pleasantness scale ( $0=$ very unpleasant, $5=$ neutral, $10=$ very pleasant). The participants were instructed to rinse their mouths out with water between each trial. The order of presentation of the pleasant/unpleasant stimuli and the order of each set of questions were randomised for each participant.

Finally, the participants were presented with each stimulus (both visual and auditory) again. For each soundtrack or image, they rated it on 7-point bipolar scales of valence (unpleasant to pleasant) and arousal (calm to exciting). We chose to ask for core affect dimensions of valence and arousal, rather than basic emotions, for greater clarity and reliability in consumer measurements (Prescott, 2017).

The experiment lasted for around 5 minutes and the participants were debriefed afterwards.

\section{Data Analysis}


Data from all 49 participants were included in the analyses, with no missing data (the computer-based questionnaire ensured that participants did not skip any ratings). A repeated-measures multivariate analysis of variance (RM-MANOVA) was conducted with 'stimulus valence' and 'stimulus modality' as within-participant factors and sour-sweet and liking ratings as measures.

To ensure that the auditory and visual stimuli were comparable in terms of valence ratings, a RM-MANOVA was conducted with stimulus valence and stimulus modality as within-participant factors, and participants' valence and arousal ratings as measures.

Finally, to test whether arousal levels of the stimuli could have influenced the participants' taste or liking ratings, linear regression tests were conducted between stimulus arousal ratings and the participants' taste and liking ratings.

\section{Results}

The mean values of the participants' taste and liking ratings for the juice samples in all conditions are shown in Figure 1, with distribution shown in Figure 2. Overall, there was a significant main effect of valence $(F(2,47)=10.02, p<.0005$, Wilks' Lambda=0.70), but not of modality $(F(2,47)<1$, n.s.), nor any interaction between valence and modality $(F(2,47)<1$, n.s.). More specifically, valence had a significant effect on both sour-sweet taste ratings $\left(F(1,48)=6.73, p=.013, \eta^{2}=0.12\right)$ and liking ratings $\left(F(1,48)=19.88, p<.0005, \eta^{2}=0.29\right)$. Participants rated the juice as being sweeter and less sour $\left(M_{\text {positive }}(S D)=4.72(2.05), M_{\text {negative }}(S D)=3.99(1.96), p=.013\right.$, Cohen's $d^{3}=0.28$ ) while exposed to more positive stimuli (the laughing image and the

\footnotetext{
3 Effect size corrected for within-participant data by taking into account the correlations between the two means (Morris \& DeShon, 2002).
} 
consonant music) as compared to the more negative stimuli (the crying image and dissonant music). In addition, they liked the juice more while exposed to the more positive stimuli than to the more negative stimuli $\left(M_{\text {positive }}(S D)=5.74(1.97)\right.$, $M_{\text {negative }}(S D)=4.77(1.80), p<.0005$, Cohen's $\left.d=0.47\right)$.

\section{INSERT FIGURES 1 \& 2 ABOUT HERE}

The mean values of the participants' valence and arousal ratings for the visual and auditory stimuli are shown in Figure 3. To ensure that the auditory and visual stimuli were comparable in terms of valence ratings, we conducted an RM-MANOVA with valence and modality as the within-participants factors, and participants' valence and arousal ratings as multivariate measures. Overall, the analysis revealed a significant main effect of valence on participants' valence ratings $(F(1,48)=367.17, p<.0005, \eta$ $\left.{ }^{2}=0.88\right)$ and arousal ratings $\left(F(1,48)=8.30, p=.006, \eta^{2}=0.15\right)$. The more pleasant stimuli (consonant music, laughing face) were rated as being significantly more pleasant than the less pleasant stimuli (dissonant music, crying image), $M_{\text {pleasant }}(S D)=5.70(1.08), M_{\text {unpleasant }}(S D)=2.12(1.06), p<.0005$, Cohen's $d=2.18$, as expected. The more pleasant stimuli were also rated as less arousing than the more unpleasant stimuli, $M_{\text {pleasant }}(S D)=3.79(1.59), \quad M_{\text {unpleasant }}(S D)=4.55(1.29), \quad p=.006$, Cohen's $d=0.34$.

There were no significant interaction effects between the valence and modality of the stimuli for valence ratings $(F(1,48)=3.19, p=.07)$, thus validating the choice of stimuli in the present study - in the sense that the stimuli only differed by valence and not by modality - so the visual and auditory stimuli had similar levels of valence. For arousal 
ratings, however, there was a significant interaction effect $(F(1,48)=10.33, p=.01, \eta$ ${ }^{2}=0.13$ ). For the pleasant stimuli, the consonant soundtrack was rated as somewhat less arousing than the laughing image $\quad\left(M_{\text {auditory }}(S D)=3.55(1.58)\right.$, $M_{\text {visual }}(S D)=4.02(1.59), p=.048$, Cohen's $\left.d=0.29\right)$. However, for the unpleasant stimuli, the dissonant soundtrack was rated as more arousing than the crying image $\left(M_{\text {auditory }}(S D)=4.78(1.25), M_{\text {visual }}(S D)=4.33(1.31), p=.035\right.$, Cohen's $\left.d=0.31\right)$. In other words, the auditory stimuli seemed to evoke greater differences in arousal as compared to the visual stimuli. Nevertheless, linear regression tests between arousal ratings and the participants' taste and liking ratings showed that perceived arousal of the audio/visual stimulus does not significantly predict sweet/sour ratings $(\beta=-0.89$, $t(194)=-1.24, p=.22)$ nor liking ratings $(\beta=-0.005, t(194)=-0.35, p=.97)$.

INSERT FIGURE 3 ABOUT HERE

\section{Discussion}

The aim of the present study was to assess whether emotionally positive or negative stimuli might influence taste evaluations regardless of the sensory modality of the external stimuli. The experiment revealed that those participants who tasted the juice mixture while presented with positively-valenced stimuli rated the juice as sweeter compared to when presented with negatively-valenced stimuli, regardless of whether the extrinsic stimuli were visual or auditory. It should, however, be noted that because the participants did not make any evaluation of the juice mixture independent of extrinsic audio/visual stimulus, it remains unclear whether the positively-valenced 
stimuli truly enhanced sweetness (or whether the negatively-valenced stimuli enhanced sourness), or whether instead both effects were in operation.

The emotional faces used in the present study were carefully chosen from the IAPS database in order to make sure that the valence levels of the visual stimuli would match those of the consonant/dissonant musical stimuli. The results revealed that this was indeed the case (see Figure 3), lending support to the hypothesis that participants were more influenced by the emotion content of the stimuli than by any modality specific traits.

The fact that valence can influence taste evaluation brings into focus sensation transfer as a possible mechanism underlying some part of the taste modulation effect reported in the introduction. In terms of auditory influences, Wang et al. (2015) demonstrated that taste-congruent soundtracks have distinct valence and arousal ratings associated with them; for instance, sweet soundtracks generally have much higher valence ratings than bitter soundtracks. In addition, those soundtracks with higher valence ratings tend to be associated (but not always) with increased food liking, and higher sweetness ratings. See Table 1 for a summary of studies involving soundtracks corresponding to sweetness, the where valence ratings of the sound stimuli were also measured.

\begin{tabular}{llllll}
\hline Paper & Increased & Increased & Auditory stimuli & Food/beverage \\
& liking? & sweetness? & & \\
\hline Reinoso-Carvalho et & al. & No & Yes & Creamy/rough & Chocolate \\
$(2017)$ & & & soundtracks & \\
Reinoso Carvalho et al. & No & Yes & Sweet/bitter & Belgian beer \\
(2016), Experiment 1 & & & soundtracks & (Taras Boulba) \\
\hline
\end{tabular}




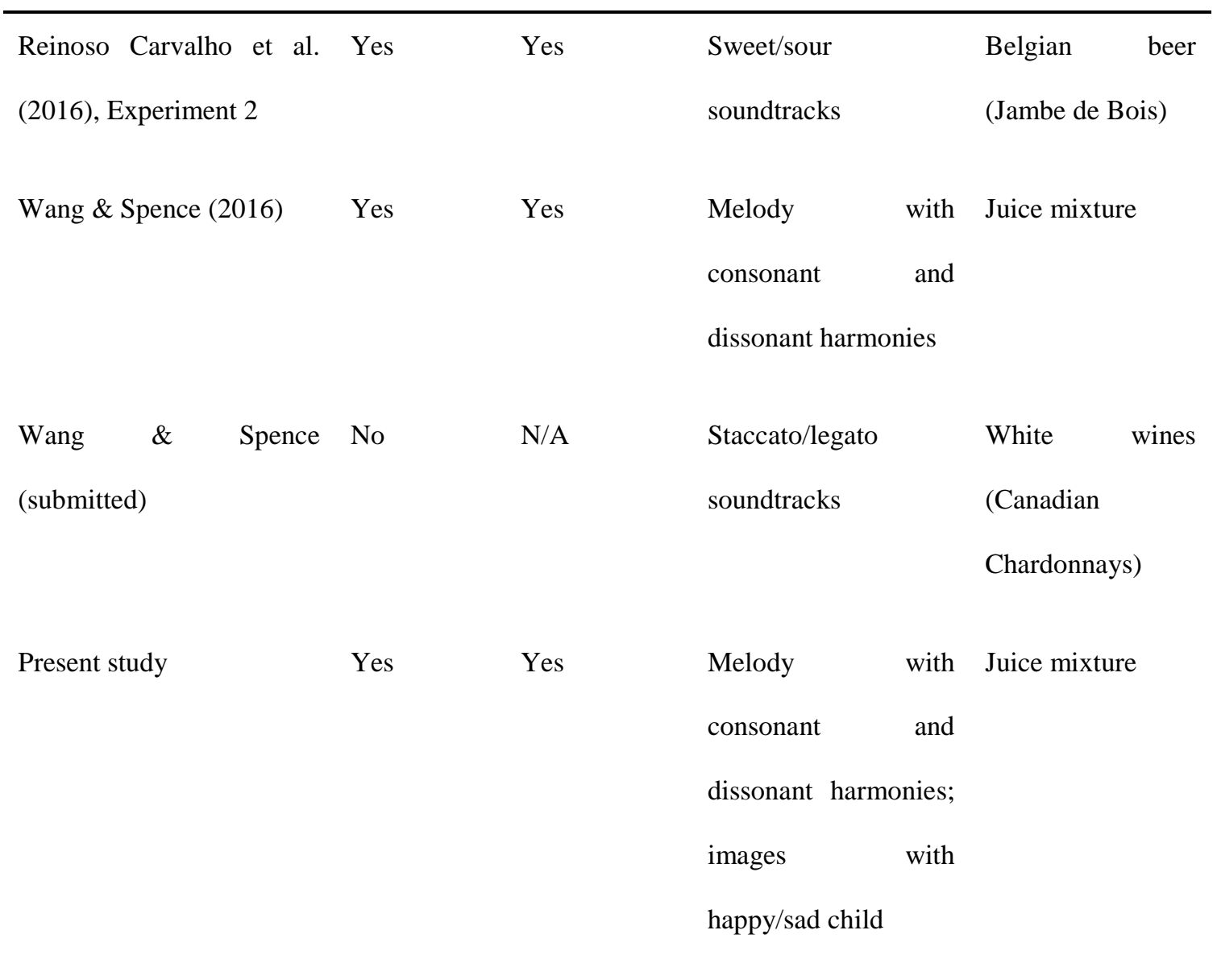

Table 1. Summary of experiments involving soundtracks corresponding to sweetness, where the valence of the auditory stimuli was measured. Columns highlight whether listening to the more pleasant soundtrack was associated with higher ratings for gustatory stimuli liking and sweetness ratings. This table demonstrates potential evidence for sensation transfer.

It is worth noting a few patterns that emerge from visual inspection of Table 1. First, the consonant/dissonant melodies used in the present study and in our previous study (Wang \& Spence, 2016) seem to influence both liking and sweetness, which falls in line with the sensation transfer theory. On the other hand, the creamy/rough soundtracks in Reinoso Carvalho et al. (2017) influenced sweetness ratings, but not liking. Similarly, the sweet soundtrack used in Reinoso Carvalho et al. (2016) enhanced sweetness, but did not consistently increase liking (depending on whether the sweet soundtrack was being compared with a sour or a bitter soundtrack). In 
conclusion, it would appear that soundtracks with clear emotional associations (e.g., consonant/dissonant harmonies) can influence both participants' hedonic as well as (sensory-discriminative) taste evaluations. With soundtracks where emotion attributes are not obviously clear to the participants (especially when the soundtracks sound quite different, as with the sweet/bitter/sour soundtracks), other mechanisms such as expectations (Wang et al., 2017) might underlie the taste modulation effect observed.

In addition, it needs to be kept in mind that, instead of priming different emotions in the mind of the taster, the emotional faces might have directly evoked associations with different basic tastes without necessarily affecting the mood of the participant. Steiner (1974) demonstrated that adults induced typical and differentiated facial expressions when tasting sweet, sour, and bitter stimuli, and that these facial stimuli are innate and present in neonates. Since then, similar studies have been repeated in newborn infants (Ganchrow, Steiner, \& Daher, 1983; Rotstein et al., 2015), children (Armstrong, Hutchinson, Laing, \& Jinks, 2007, for children aged 6-9 years), and even newborn primates (Ueno, Ueno, \& Tomonaga, 2004). More specifically, tasting sweet stimuli induced upward mouth angles resembling a smile, whereas sour tastes elicited a pursing of the lips instead (Steiner, 1974). The pleasant image used in the present study featuring a smiling face, therefore, corresponds to the natural expression from eating sweet foods. In order to conclude that the emotional content of the pictures and not necessarily the facial expressions themselves - were responsible for the taste modulation effects observed here, one would obviously need to run a future study controlling for the mood of the participants (by measuring their mood before and after each trial, for instance).

Furthermore, it is worth noting that viewing emotional faces (in the context of someone eating) have also been demonstrated to influence people's desire to eat 
certain foods (Barthomeuf, Rousset, \& Droit-Volet, 2008, 2012; Poor, Duhachek, \& Krishnan, 2013; Rousset, Schlich, Chatonnier, Barthomeuf, \& Droit-Volet, 2008). In particular, looking at pictures of someone making a disgusted face while eating a liked food was shown to decrease the viewer's desire to eat those foods, whereas looking at pictures of an eater with a pleasurable expression did not enhance desire to eat the same liked foods (Barthomeuf et al., 2008). Conversely, when the food itself was disliked, the desire to eat was significantly increased when participants viewed an image of an eater with a positive expression, but disgust did not influence the desire to eat. In the context of the present study, assuming that participants find juice pleasant, it is possible that the sad face (i.e., the negative visual stimulus) could have decreased desire to eat, and hence made the juice less pleasant.

In addition to valence, we took arousal into account as an important emotional component of the extrinsic audio/visual stimuli. Overall, the unpleasant stimuli were more arousing than the pleasant stimuli (of both modalities). A comparison of 24 soundtracks composed to match specific basic tastes (sweet, sour, salty, bitter, umami) by Wang et al. (2015) demonstrated that associations between soundtracks and sourness are partly mediated by arousal; in other words, participants tended to associate more arousing soundtracks with sourness. It is therefore possible that arousal, in addition to valence, is playing a role in the differences in the participants evaluations of the sweet-sour balance in the juice samples. However, regression analysis did not reveal a significant relationship between arousal and taste ratings (nor between arousal and liking ratings).

The present study demonstrated that the valence of an extrinsic stimulus could influence food/drink evaluation for both visual and auditory modalities. This result is likely to be especially important for innovators in the restaurant/food industries. It 
follows that all aspects of the environment - whether packaging, or background music, or the choice of decorations on the wall - could influence the experience of eating/drinking. Furthermore, the idea of manipulating the valence of an extrinsic stimulus can potentially be extended to the tactile modality as well, in what's been termed affective ventriloquism by Spence and Gallace (2011). For instance, might the same juice mixture taste sweeter if consumed from a cup with a pleasant texture (e.g., smooth, velvety, or fuzzy) compared to one with an unpleasant texture (e.g., rough, slimy, or sticky; cf. Biggs, Juravle, \& Spence, 2016; Marinetti, 1932/2014)? Finally, the question remains as to whether combining congruent stimuli from multiple sensory modalities could have a more powerful impact on the taste experience. For instance, Spence et al. (2014) demonstrated that congruent combinations of coloured lights and music (for instance, red lighting and 'sweet' music) influences the wine drinking experience more than do coloured lights alone. In the context of the current study, might there be an additive effect of sweetness enhancement if participants were presented with both consonant music and a happy image at the same time?

Acknowledgements: CS would like to thank the AHRC grant entitled 'Rethinking the senses' (AH/L007053/1) for supporting this research. 


\section{REFERENCES}

Armstrong, J. E., Hutchinson, I., Laing, D. G., \& Jinks, A. L. (2007). Facial electromyography: Responses of children to odor and taste stimuli. Chemical Senses, 32, 611-621.

Barthomeuf, L., Rousset, R., \& Droit-Volet, S. (2009). Emotion and food. Do the emotions expressed on other people's faces affect the desire to eat liked and disliked food products? Appetite, 52, 27-33.

Barthomeuf, L., Rousset, R., \& Droit-Volet, S. (2012). How emotions expressed by adults' faces affect the desire to eat liked and disliked foods in children compared to adults. British Journal of Developmental Psychology, 30, 253-266.

Battacharya, J., \& Lindsen, J. P. (2016). Music for a brighter world: Brightness judgment bias by musical emotion. PLOS ONE, 11:e0148959.

Becerril, K., \& Barch, D. (2011). Influence of emotional processing on working memory in schizophrenia. Schizophrenia Bulletin, 37, 1027-1038.

Bidelman, G. M., \& Krishnan, A. (2009). Neural correlates of consonance, dissonance, and the hierarchy of musical pitch in the human brainstem. Journal of Neuroscience, 29, 13165-13171.

Biggs, L., Juravle, G., \& Spence, C. (2016). Haptic exploration of plateware alters the perceived texture and taste of food. Food Quality \& Preference, 50, 129-134.

Blood, A. J., Zatorre, R. J., Bermudez, P., \& Evans, A. C. (1999). Emotional responses to pleasant and unpleasant music correlate with activity in paralimbic brain regions. Nature Neuroscience, 2, 382-387. 
Bredie, W. L. P., Tan, H. S. G., \& Wendin, K. (2014). A comparative study on facially expressed emotions in response to basic tastes. Chemosensory Perception, 7, 1-9.

Carminati, M. N., \& Knoeferle, P. (2013). Effects of speaker emotional facial expression and listener age on incremental sentence processing. PLoS ONE, 8:e72559.

Cheskin, L. (1972). Marketing success: How to achieve it. Boston, MA: Cahners Books.

de Gelder, B., \& Vroomen, J. (2000). The perception of emotions by ear and by eye. Cognition and Emotion, 14, 289-311.

Derntl, B., Habel, U., Windischberger, C., Robinson, S., Kryspin-Exner, I, ..., Moser, E. (2009). General and specific responsiveness of the amygdala during explicit emotion recognition in females and males. BMC Neuroscience, 10:91.

Ethofer, T., Anders, S., Erb, M., Droll, C., Royen, L., Saur, R., et al. (2006). Impact of voice on emotional judgment of faces: An event-related fMRI study. Human Brain Mapping, 27, 707-714.

Ganchrow, J. R., Steiner, J. E., \& Daher, M. (1983). Neonatal facial expressions in response to different qualities and intensities of gustatory stimuli. Infant Behavior and Development, 6, 189-200.

Gerdes, A. B. M., Wieser, M. J., \& Alpers, G. W. (2014). Emotional pictures and sounds: A review of multimodal interactions of emotion cues in multiple domains. Frontiers in Psychology, 5:1351. 
Knoeferle, K. M., Woods, A., Käppler, F., \& Spence, C. (2015). That sounds sweet: Using crossmodal correspondences to communicate gustatory attributes. Psychology \& Marketing, 32, 107-120.

Knöferle, K. M., \& Spence, C. (2012). Crossmodal correspondences between sounds and tastes. Psychonomic Bulletin \& Review, 19, 992-1006.

Lang, P. J., Bradley, M. M., \& Cuthbert, B. N. (2008). International affective picture system (IAPS): Affective ratings of pictures and instruction manual. Technical report A-8. Gainesville, FL: University of Florida.

Liang, P., Biswas, P., Vinnakota, S., Fu, L., Chen, M., Quan, Y., Zhan, Y., Zhang, G., \& Roy, S. (2016). Invariant effect of vision on taste across two Asian cultures: India and China. Journal of Sensory Studies, 31, 416-422.

Liang, P., Roy, S., Chen, M.-L., \& Zhang, G.-H. (2013). Visual influence of shapes and semantic familiarity on human sweet sensitivity. Behavioural Brain Research, 253, 42-47.

Logeswaran, N., \& Bhattacharya, J. (2009). Crossmodal transfer of emotion by music. Neuroscience Letters, 455, 129-133.

Marinetti, F. T. (1932/2014). The futurist cookbook (Trans. S. Brill, 1989). London, UK: Penguin Books.

Massaro, D. W., \& Egan, P. B. (1996). Perceiving affect from the voice and the face. Psychonomic Bulletin and Review, 3, 215-221.

Mesz, B., Trevisan, M. A., \& Sigman, M. (2011). The taste of music. Perception, 40, 209-219. 
Morris, S. B., \& DeShon, R. P. (2002). Combining effect size estimates in metaanalysis with repeated measures and independent-groups designs. Psychological Methods, 7, 105-125.

Ngo, M. K., Velasco, C., Salgado, A., Boehm, E., O’Neill, D., \& Spence, C. (2013). Assessing crossmodal correspondences in exotic fruit juices: The case of shape and sound symbolism. Food Quality \& Preference, 28, 361-369.

Palmer, S. E., Schloss, K. B., Xu, Z., \& Prado-León, L. R. (2013). Music-color associations are mediated by emotion. Proceedings of the National Academy of Sciences of the USA, 110, 8836-8841.

Poor, M., Duhachek, A., \& Krishnan, H. S. (2013). How images of other consumers influence subsequent taste perceptions. Journal of Marketing, 77, 124-139.

Prescott, J. (2017). Some considerations in the measurement of emotions in sensory and consumer research. Food Quality and Preference, 62, 360-368.

Reinoso Carvalho, F., Wang, Q. (J.), van Ee, R., Persoone, D., \& Spence, C. (2017). "Smooth operator": Music modulates the perceived creaminess, sweetness, and bitterness of chocolate. Appetite, 108, 383-390.

Reinoso Carvalho, F., Wang, Q. (J.), Van Ee, R., \& Spence, C. (2016). The influence of soundscapes on the perception and evaluation of beers. Food Quality and Preference, 52, 32-41.

Rotstein, M., Stolar, O., Uliel, S., Mandel, D., Mani, A., Dollberg, S., ..., Leitner, Y. (2015). Facial expression in response to smell and taste stimuli in small and appropriate for gestional age newborns. Journal of Child Neurology, 30, 14661471. 
Rousset, S., Schlich, P., Chatonnier, A., Barthomeuf, L., \& Droit-Volet, S. (2008). Is the desire to eat familiar and unfamiliar meat products influenced by the emotions expressed on eaters’ faces? Appetite, 50, 110-119.

Salgado-Montejo, A., Alvarado, J. A., Velasco, C., Salgado, C. J., Hasse, K., \& Spence, C. (2015a). The sweetest thing: The influence of angularity, symmetry, and the number of elements on shape-valence and shape-taste matches. Frontiers in Psychology, 6:1382.

Salgado-Montejo, A., Leon, I. T., Elliot, A., Salgado, C. J., \& Spence, C. (2015b). Smiles over frowns: Curved lines can influence product preference. Psychology \& Marketing, 32, 771-781.

Spence, C., \& Gallace, A. (2011). Multisensory design: Reaching out to touch the consumer. Psychology \& Marketing, 28, 267-308.

Spence, C., \& Piqueras-Fiszman, B. (2014). The perfect meal: The multisensory science of food and dining. Oxford, UK: John Wiley \& Sons.

Spence, C., Velasco, C., \& Knoeferle, K. (2014). A large sample study on the influence of the multisensory environment on the wine drinking experience. Flavour, 3:8.

Steiner, J. E. (1974). Innate, discriminative human facial expressions to taste and smell stimulation. Annals New York Academy of Sciences, 237, 229-233.

Turek, R. (1996). The elements of music: Concepts and applications, Volume 1. Akron, OH: McGraw-Hill. 
Ueno, A., Ueno, Y., Tomonaga, M. (2004). Facial responses to four basic tastes in newborn rhesus macaques (Macaca mulatta) and chimpanzees (Pan troglodytes). Behavioural Brain Research, 154, 261-271.

Van den Stock, J., Grèzes, J., \& de Gelder, B. (2008). Human and animal sounds influence recognition of body language. Brain Research, 1242, 185-190.

Van den Stock, J., Righart, R., \& de Gelder, B. (2007). Body expressions influence recognition of emotions in the face and voice. Emotion, 7, 487-494.

Velasco, C., Salgado-Montejo, A., Marmolejo-Ramos, F., \& Spence, C. (2014). Predictive packaging design: Tasting shapes, typefaces, names, and sounds. Food Quality and Preference, 34, 88-95.

Velasco, C., Woods, A. T., Hyndman, S., Spence, C. (2015). The taste of typeface. $i-$ Perception, 6:4.

Wang, Q. (J.), Keller, S., \& Spence, C. (2017). The sound of spiciness: Enhancing the evaluation of piquancy by means of a customized crossmodally congruent soundtrack. Food Quality and Preference, 58, 1-9.

Wang, Q. (J.), \& Spence, C. (2016). 'Striking a sour note': Assessing the influence of consonant and dissonant music on taste perception. Multisensory Research, 29, 195-208.

Wang, Q. (J.), \& Spence, C. (submitted). Assessing the influence of music on wine perception amongst wine professionals. Food Science and Nutrition. 
Wang, Q. (J.), Woods, A., \& Spence, C. (2015). “What's your taste in music?” A comparison of the effectiveness of various soundscapes in evoking specific tastes. i-Perception, 6:6.

Winkielman, P., Berridge, K. C., \& Wilbarger, J. L. (2005). Unconscious affective reactions to masked happy versus angry faces influence consumption behavior and judgments of value. Personality \& Social Psychology Bulletin, 31, 121135.

Zentner, M. R., \& Kagan, J. (1998). Infants’ perception of consonance and dissonance in music. Infant Behavior and Development. 21, 483-492. 
Figure 1. Mean values of sour-sweet (A) and liking (B) ratings for juice samples tasted while experiencing external stimuli of both modality (visual, auditory) and valence (pleasant, unpleasant) types in the present study. Error bars indicate standard error. Asterisk ‘*’, indicates statistical significance at $\mathrm{p}<.05$.

Figure 2. Comparative histograms of comparing the effect of pleasant and unpleasant extrinsic stimuli in both visual and auditory modalities. Participants’ ratings for sour-sweet (A for vision, B for audition) and liking ( $\mathrm{C}$ for vision, D for audition) are both shown. For taste ratings, 1 indicates much more sour than sweet, while 9 indicates much more sweet than sour. For liking ratings, 1 indicates strongly dislike and 9 indicates strongly like.

Figure 3. Mean values of valence (A) and arousal (B) ratings of the visual and auditory stimuli used in the present study, categorised by modality (visual, auditory) and valence (unpleasant, pleasant). Error bars indicate standard error. Asterisk '*’, indicates statistical significance at $\mathrm{p}<.05$. 
Figure 1

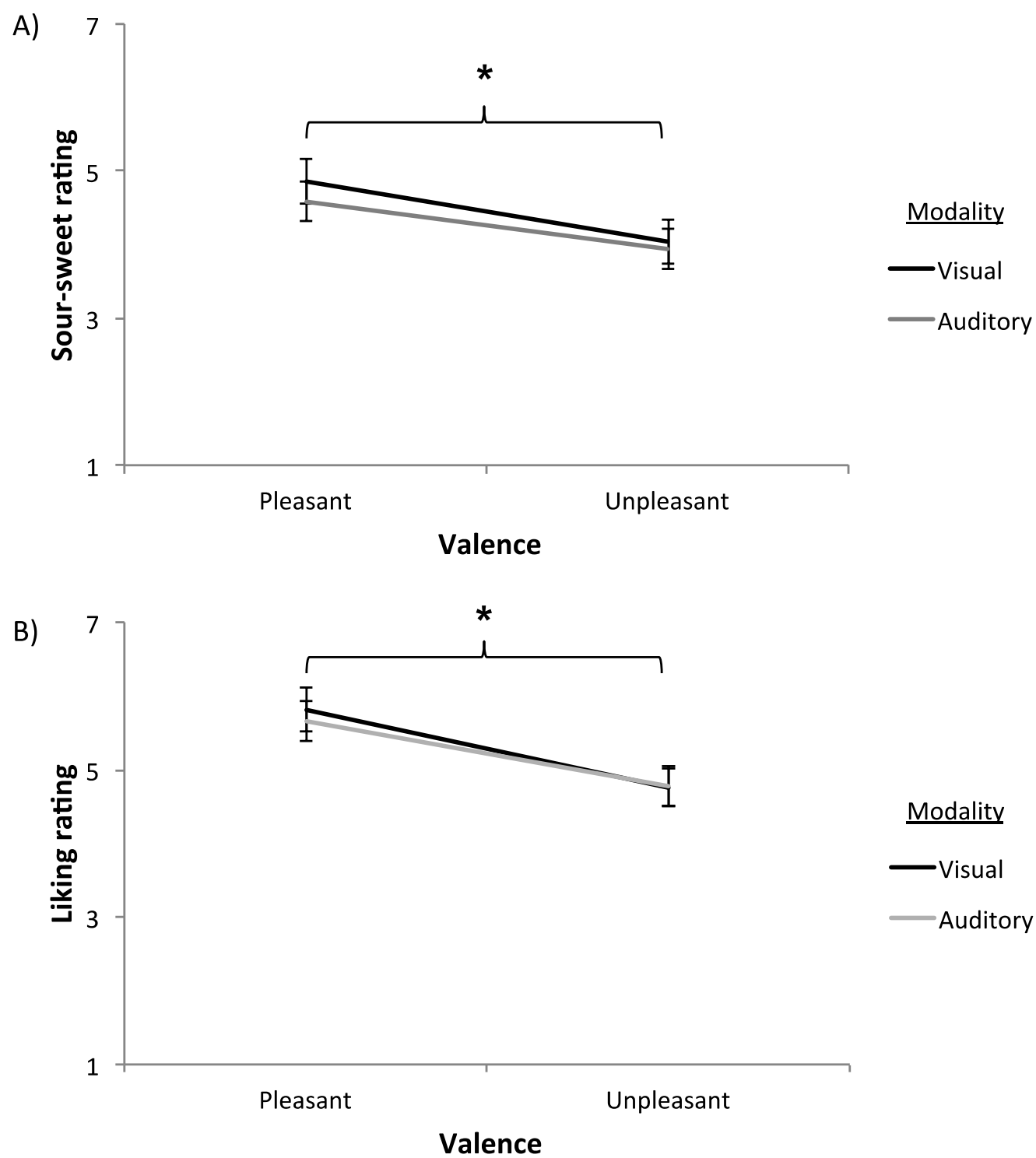


Figure 2
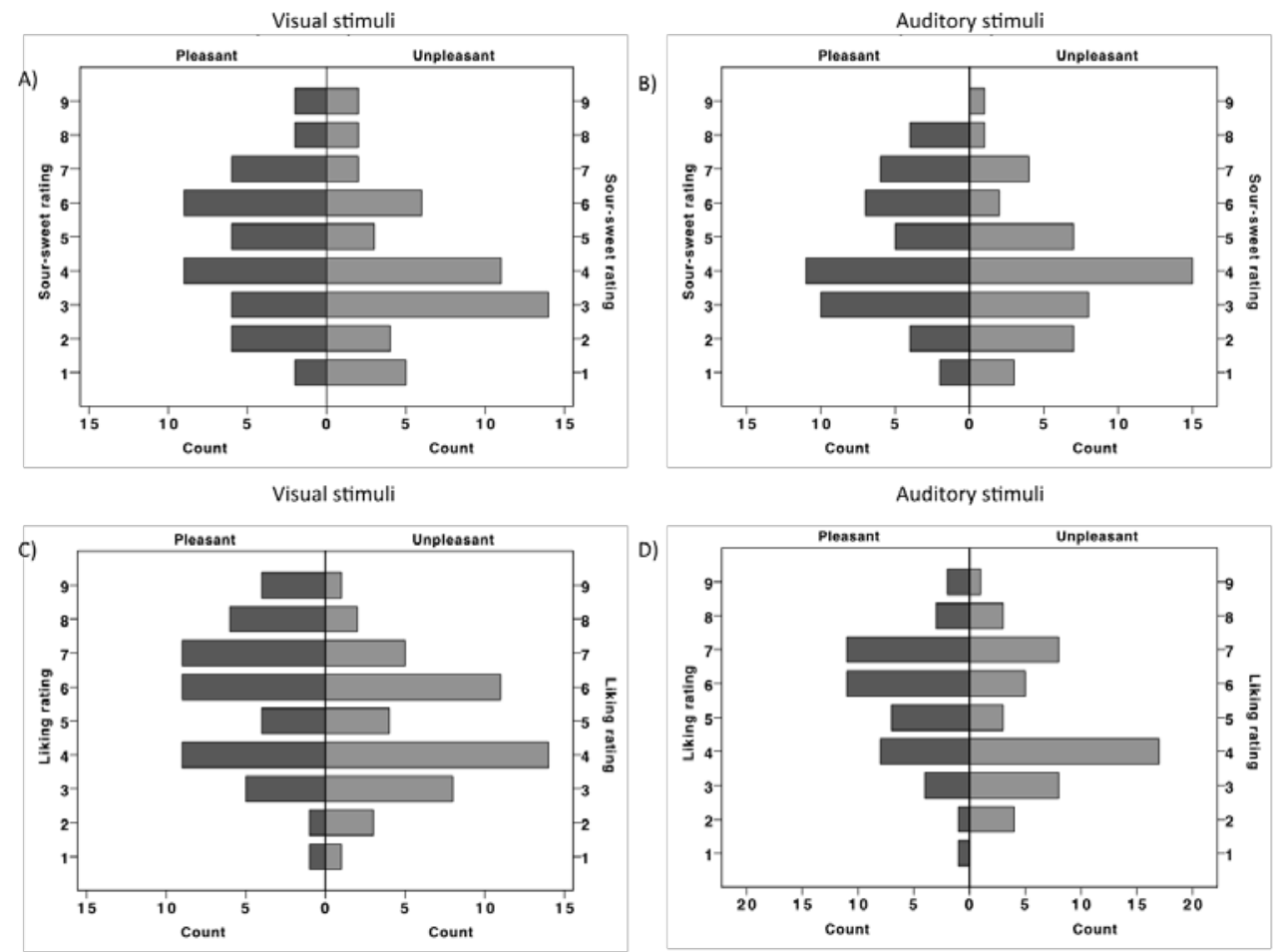
Figure 3

A)

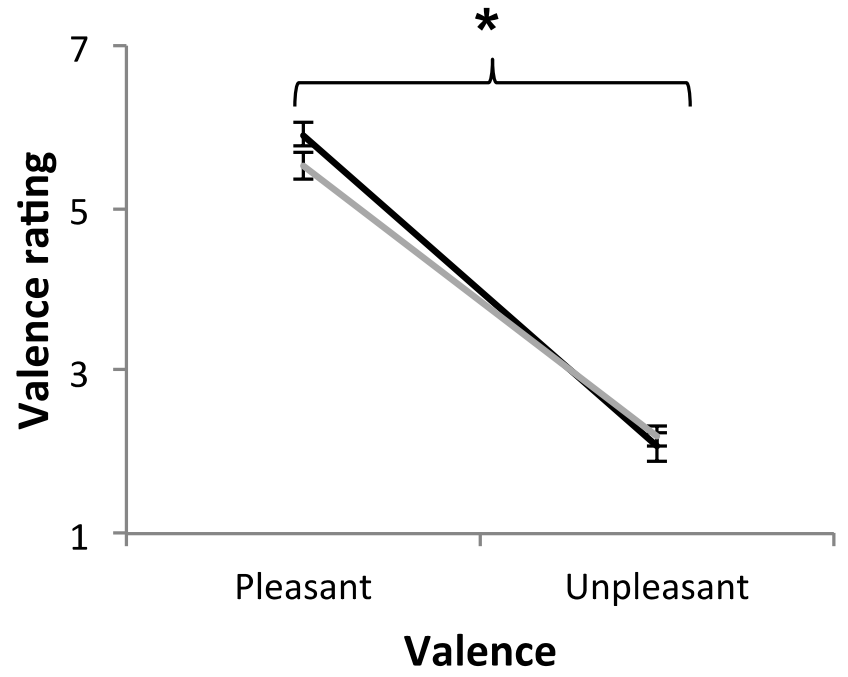

Modality

- Visual

—Auditory

B)

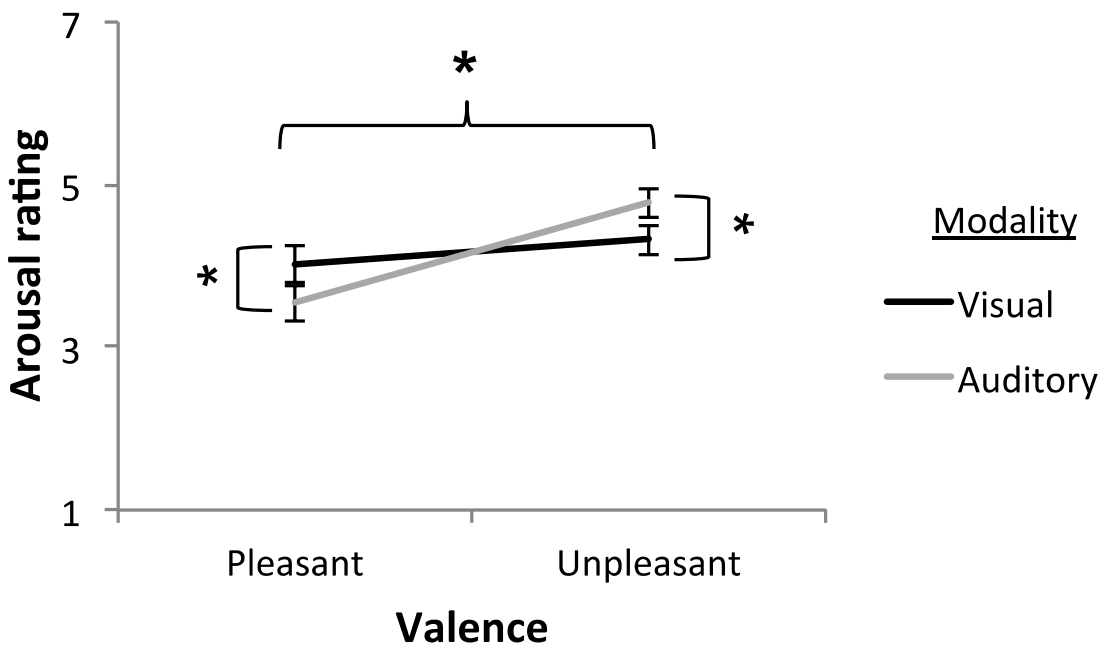

